\title{
PERANCANGAN SISTEM INFORMASI ABSENSI BERBASIS JAVA NETBEANS PADA PT. LOTTE SHOPPING INDONESIA
}

\author{
Muhamad Rifki ${ }^{1}$, Imam Himawan $^{2}$, Lin Suciani Astuti ${ }^{3}$ \\ 1,2,3 Teknik Informatika, Fakultas Teknik dan Ilmu Komputer, Universitas Indraprasta PGRI \\ Jalan Raya Tengah No 80, Kelurahan Gedong, Pasar Rebo, Jakarta Timur

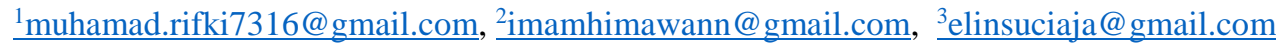

\begin{abstract}
ABSTRAK
Perkembangan teknologi khususnya teknologi komputer telah mengalami kemajuan yang sangat pesat. Teknologi tersebut tidak lepas dari peran manusia yang setiap saat terus memperbaiki dan mencari inovasi baru agar teknologi tersebut dapat digunakan untuk membantu pekerjaan manusia. Khususnya kemajuan dibidang teknologi informasi terutama pada teknologi mobile dan internet. Teknologi dapat membuat pekerjaan menjadi lebih mudah dan efisien, manfaat penelitian ini untuk memudahkan proses sistem pendataan menjadi komputerisasi dalam pengolahan data absensi. Pengolahan absensi PT. Lotte Shopping Indonesia yang masih menggunakan cara manual yang menyebabkan lambatnya pengolahan data yang tidak terstruktur dengan baik. Tujuan penelitian ini untuk mengatasi permasalahan yang ada, dengan merancang sistem pengolahan data absensi karyawan secara terintegrasi dan terorganisir lebih baik dengan memanfaatkan teknologi informasi yang sudah berkembang pesat. Metode penelitian yang digunakan yaitu kualitatif deskriptif yaitu penelitian yang menggambarkan tentang suatu kegiatan pada perusahaan. Membangun sistem ini menggunakan alat sistem yaitu Diagram Alir Data (DAD), Konteks, dan Nol dengan menggunakan bahasa database MySQL menggunakan XAMPP. Kesimpulan dari penelitian ini Adalah dengan diterapkannya dapat mempermudah proses pengumpulan data sistem yang ada pada aplikasi absensi sudah terkomputerisasi, efisien dalam penyimpanan data dan laporan.
\end{abstract}

Kata Kunci : Sistem Informasi, Absensi, Java, Netbeans

\section{ABSTRACT}

The developments of technology, especially computer technology has progressed very rapidly. The technology cannot be separated from the role of humans who are constantly improving and looking for new innovations so that the technology can be used to help human work. Especially advances in the field of information technology, especially in mobile technology and the internet. Technology can make work easier and more efficient, the purpose of this research is to facilitate the process of the data collection system being computerized in the processing of attendance data. Attendance processing PT. Lotte Shopping Indonesia, which still uses manual methods, causes slow processing of unstructured data. The purpose of this study is to overcome existing problems, by designing an integrated and better organized employee attendance data processing system by utilizing information technology that has developed rapidly. The research method used is descriptive qualitative research that describes an activity in the company. Building this system using system tools, namely Data Flow Diagram (DAD), Context, and Zero using the MySQL database language using $X A M P P$. the conclusion of this study is that the implementation can simplify the process of collecting data, the existing system in the attendance application is computerized, efficient in data storage and reports.

Key Word: Information System, Attendance, Java, Netbeans

\section{PENDAHULUAN}

Absensi sebuah kegiatan pengambilan data guna mengetahui jumlah kehadiran pada setiap pekerjaan. Absensi digunakan untuk mencatat kehadiran karyawan, manager, maupun anggota dan berserta jajaran staff lainnya. Seiring perkembangan teknologi yang begitu pesat, informasi dimanfaatkan sebagai sarana peningkatan informasi. Pemanfaatan tersebut mempermudah suatu pekerjaan seperti pengolahan data lebih cepat, keputusan yang akan diambil lebih tepat, menghemat waktu dan biaya. Selain itu informasi yang dapat diakses oleh pengguna internet yang semakin lama semakin luas. Dengan penggunaan sistem yang terkomputerisasi akan menghasilkan keakuratan penyajian data.

PT. Lotte Shopping Indonesia merupakan sebuah perusahaan yang bergerak dibidang grosir(whosale). Dimana pengolahan datanya masih kurang efektif dan efisien. Semua 
masih dilakukan secara manual mulai dari pendataan jam masuk, jam pulang, dan perhitungan gaji. Serta bentuk laporan absensi yang dibuat berupa hardcopy yang dapat menyebabkan kesalahan dalam pencarian data dan dapat dikhawatirkan terjadi kehilangan data absensi. Berdasarkan latar belakang diatas maka penulis mengangkat masalah tentang pembuatan sebuah data yang disimpan dalam suatu database sebagai laporan yang berjudul "Perancangan Sistem Informasi Absensi Berbasis Java Netbeans pada PT. Lotte Shopping Indonesia". Aplikasi ini dikembangkan memanfaatkan teknologi informasi berbasis java, yaitu menggunakan Java Netbeans sebagai bahasa pemrograman dan menggunakan MySQL untuk pengolahan database.

Menurut (Rusmawan 2019) Perancangan adalah sebuah proses untuk mendefinisikan sesuatu yang akan dikerjakan dengan menggunakan teknik yang bervariasi serta didalamnya melibatkan deskripsi mengenai arsitektur dengan detail komponen dan juga keterbatasan yang akan dialami dalam proses pengerjaannya.

Menurut (Agus 2009) proses perancangan bisa melibatkan pengembangan beberapa model sistem pada tingkat abstraksi yang berbeda-beda.

Menurut (Jogiyanto 2008) Sistem adalah suatu jaringan kerja dari prosedur-prosedur yang saling berhubungan, berkelompok bersama-sama untuk melakukan suatu kegiatan atau untuk menyelesaikan suatu sasaran tertentu.

Menurut

Menurut (A.S 2016) sistem adalah perancangan dalam pembangunan perangkat lunak merupakan upaya untuk mengkonstruksi sebuah sistem yang memberikan kepuasan (mungkin informal) akan spesifikasi kebutuhan fungsional.

Menurut (Soeherman 2008) sistem informasi merupakan serangkaian komponen berupa manusia, prosedur data dan teknologi (seperti komputer) yang digunakan untuk melakukan sebuah proses untuk pengambilan keputusan guna penunjangan keberhasilan bagi setiap organisasi.
Menurut (Ida Nuraida 2008) sistem informasi merupakan perangkat prosedur yang terorganisasi dengan sistematik, bila dilaksanakan akan menyediakan informasi yang dapat dimanfaatkan dalam proses pembuatan keputusan.

Menurut (Mulyani 2016) Sekelompok yang erat berhubungan satu dengan yang lain, yang berfungsi bersama sama untuk mencapai suatu tujuan tertentu.

Menurut (Jogiyanto 2008) pendekatan yang menekankan pada prosedurnya dan pendekatan yang menekankan pada komponen atau elemennya.

Menurut (Oktafianto and Muslihudin 2016) Informasi merupakan hasil pengolahan data sehingga menjadi bentuk yang penting bagi penerimanya dan mempunyai kegunaan sebagai dasar dalam pengambilan keputusan yang dapat dirasakan akibatnya secara lengsung saat itu juga atau secara tidak langsung pada saat mendatang.

Absensi merupakan suatu kegiatan atau rutinitas yang dilakukan oleh pegawai untuk membuktikan dirinya hadir berkerja atau tidak hadir berkerja ditentukan oleh masing-masing perusahaan atau institusi. Absensi digunakan untuk mencatat jam hadir setiap karyawan.

Menurut (Hasibuan Malayu S.P 2009) Karyawan adalah orang penjual jasa (Pikiran atau tenaga) dan mendapat konpensasi yang besarnya telah ditetapkan terlebih dahulu.

Netbeans adalah Integrated Development Environment (IDE) berbasiskan java dari Sun Mircrosystem yang berjalan diatas swing. Swing merupakan sebuah teknologi Java untuk pengembangan aplikasi desktop yang dapat berjalan diberbagai macam platforms, seperti windows, linux, Mac OS X, and Solaris (Bay Haqi 2019).

Xampp adalah perangkat lunak bebas (free software) yang mendukung banyak sistem operasi, merupakan kompilasi dari beberapa program. Fungsi XAMPP sendiri sebagai server yang berdiri sendiri (localhost), yang terdiri dari beberapa program, antara lain: Appache HTTP Server. MySQL database, 
dan penerjemah bahasa yang ditulis dengan pemrograman PHP dan Perl (Bay Haqi 2019).

MySQL adalah suatu perangkat lunak database relasi (Relational DataBase Management System atau RDBMS) seperti halnya oracle, postgresql, ms sql dan sebagainya (Bay Haqi 2019).

\section{METODE PENELITIAN}

Waktu penelitian yang digunakan selama empat bulan dimulai dari bulan april 2021 sampai dengan bulan agustus.

Metode yang digunakan adalah penelitian kualitatif deskriptif, yaitu penelitian yang menggambarkan tentang suatu kegiatan pada perusahaan. Penelitian ini bertujuan untuk menggambarkan tentang kegiatan yang telah berlangsung pada saat studi.

Metode Pengumpulan:

1. Observasi: Pengumpulan data dilakukan dengan cara pengamatan langsung ditempat penelitian.

2. Wawancara: Penelitian ini menggunakan wawancara langsung dengan Karyawan perusahaan PT. Lotte Shopping Indonesia untuk mengetahui informasi mengenai absensi.

3. Study Keputusan dilakukan dengan mengumpulkan data dan informasi dari kutipan buku serta beberapa hasil penelitian yang berkaitan.

\section{HASIL DAN PEMBAHASAN}

Aplikasi sistem informasi absensi karyawan berbasis java netbeans yang terkomputerisasi sehingga dapat dihasilkan informasi yang lebih cepat, tepat dan akurat:

1. Membangun sistem informasi yang sudah terkomputerisasi yang dapat membantu kinerja admin dalam pendataan absensi, Transaksi, pembuatan laporan absensi karyawan, pembuatan Jam Masuk dan Jam Keluar dan pembuatan daftar absensi karyawan yang sudah melakukan absensi.

2. Perancangan database sistem untuk penyimpanan data agar lebih efisien dan lebih akurat, serta dapat mengurangi adanya kemungkinan kehilangan data.

3. Pembuatan sistem informasi yang dapat dimengerti oleh semua pihak karyawan PT. Lotte Shopping Indonesia.

\section{Dekomposisi $\quad$ Fungsi $\quad$ Sistem yang Diusulkan}

Dekomposisi fungsi dimaksudkan untuk mengetahui gambaran fungsi-fungsi proses dan bentuk masukan serta keluaran yang terdapat pada sistem yang akan dijalankan. Berikut ini gambaran dari dekomposisi fungsi sistem:

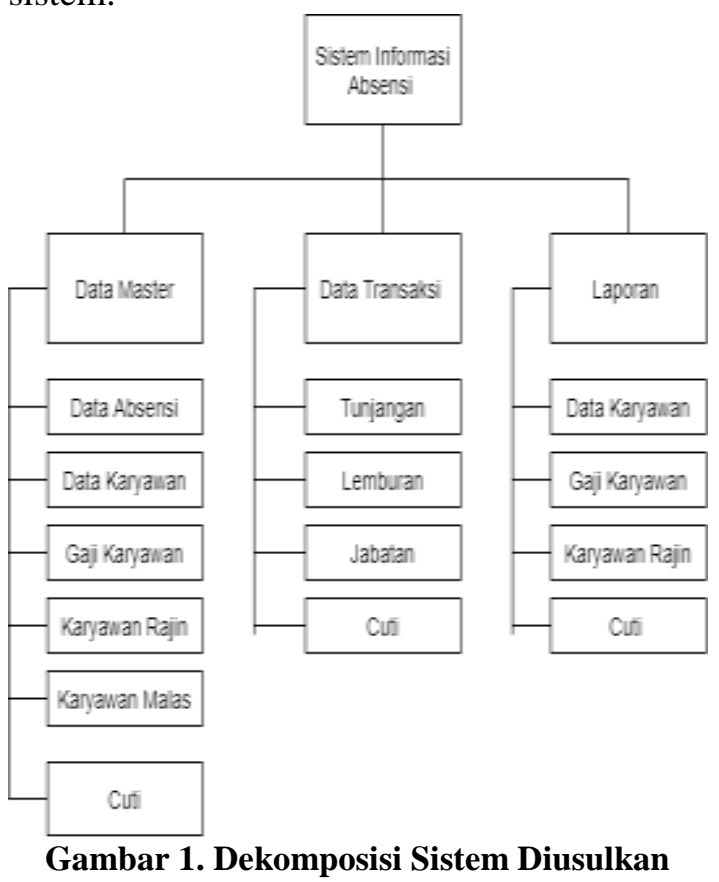

\section{Diagram Konteks yang Diusulkan}

Aliran data sistem yang diusulkan berikutnya digambarkan pada diagram konteks berikut :

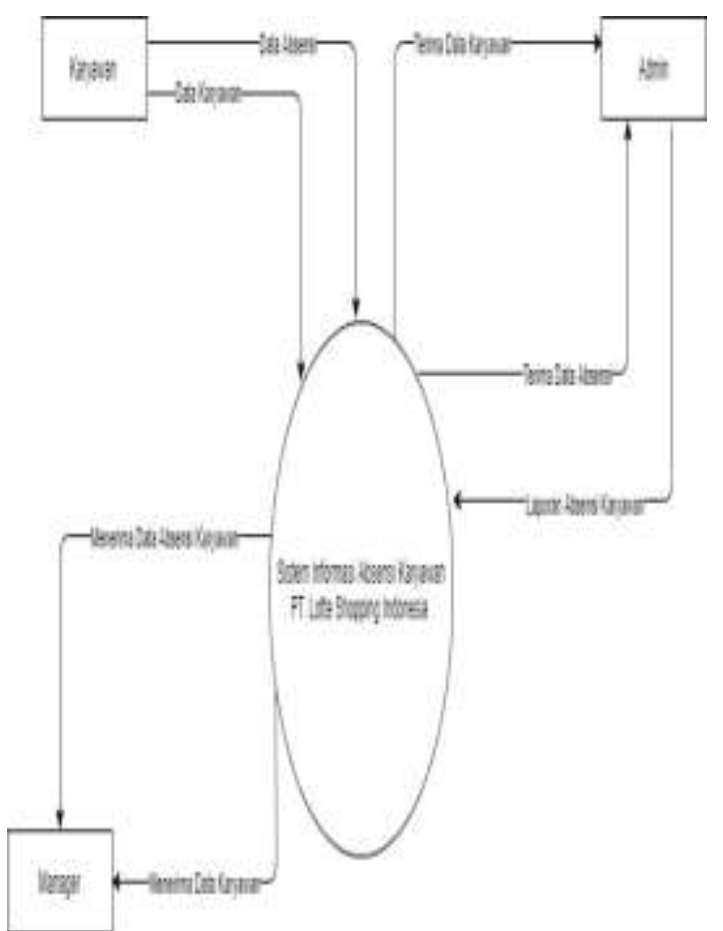

Gambar 2. Diagram Konteks yang Diusulkan 
Tampilan Layar Login

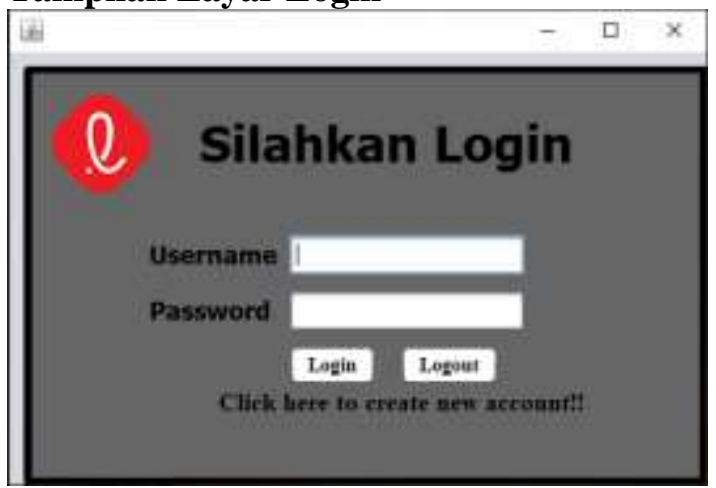

Gambar 3. Tampilan Layar Menu Login

Menu login Admin digunakan sebagai kata kunci sebelum admin memasuki program utama. Menu ini bertujuan untuk mengamankan program supaya tidak dapat diakses oleh orang lain kecuali admin.

\section{Tampilan Layar Menu Utama}

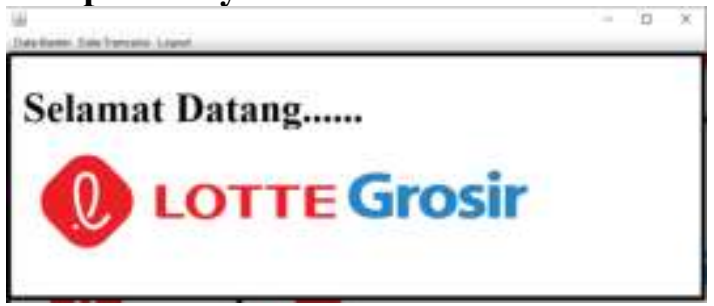

Gambar 4. Tampilan Layar Menu Utama

Menu diatas menampilkan tampilan menu utama sistem informasi absensi karyawan. Menu ini berfungsi untuk memasukkan datadata yang berkaitan dengan Data Absensi, Data Karyawan, Data Gaji Karyawan, Data Karyawan Rajin, Data Karyawan Malas, Data Cuti.

\section{Tampilan Layer Data Absensi}

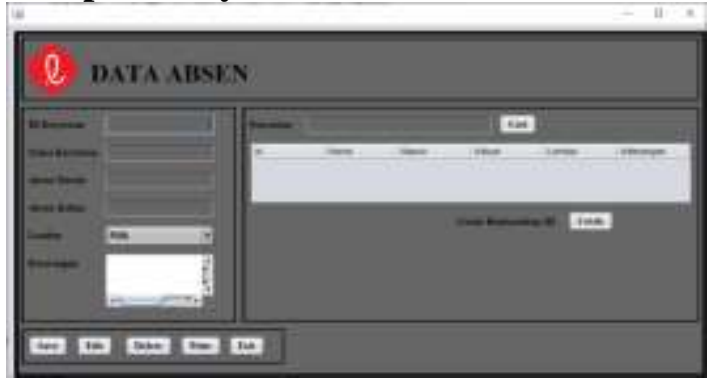

Gambar 5. Tampilan Layer Data Absensi

Pada Tampilan layer ini admin dapat menginput Data Absensi, Melakukan perubahan Data Absensi serta dapat menghapus Data Absensi. Dan juga dapat mencetak data absensi.
Tampilan Layer Data Karyawan

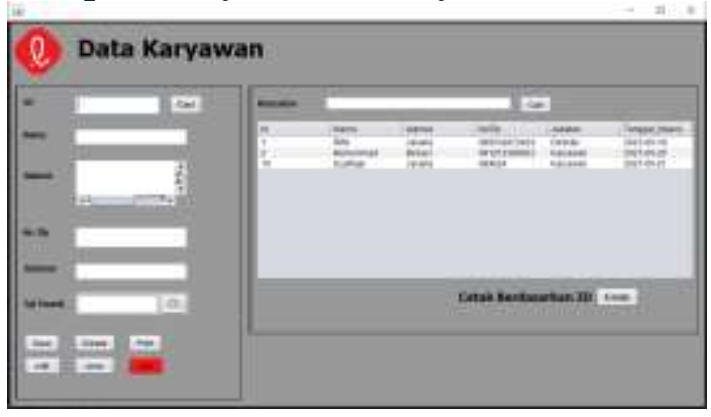

Gambar 6. Tampilan Layer Karyawan

Pada tampilan layer ini admin dapat menginput Data Karyawan , siapa saja yang sudah mulai bekerja dan sudah resmi menjadi karyawan di PT. Lotte Shopping Indonesia.

\section{Tampilan Layer Transaksi}

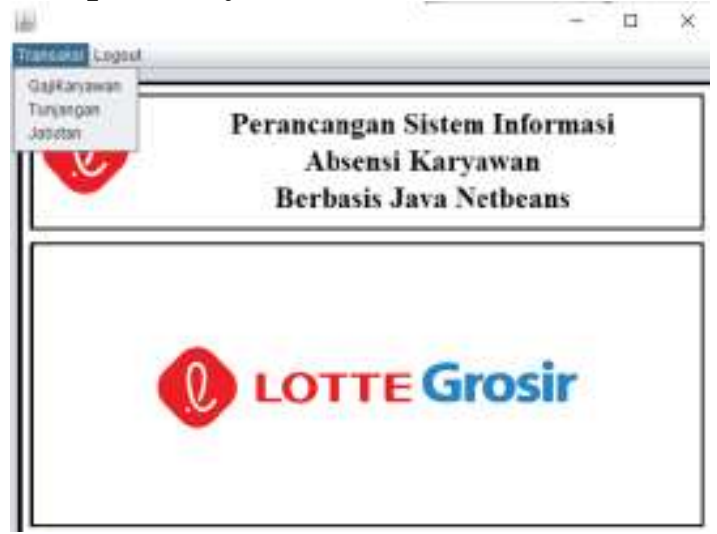

Gambar 7. Tampilan Layer Transaksi

Pada tampilan layer ini admin dapat menginput transaksi gaji karyawan, tunjangan, jabatan, serta melakukan perubahan pada transaksi tersebut serta dapat menghapus transaksi data yang sudah diinput, dan juga dapat mencetak transaksi yang sudah diinput.

\section{Tampilan Laporan Transaksi}

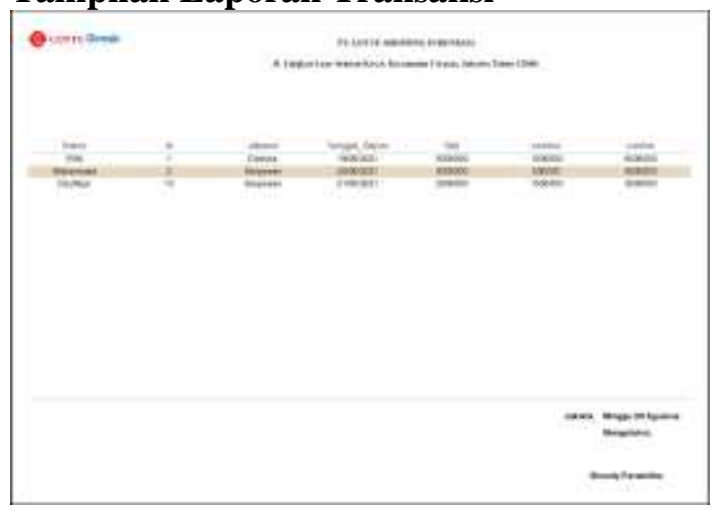

Gambar 8. Tampilan Output Transaksi

Pada tampilan ini admin dapat memberikan laporan transaksi gaji karyawan kepada 
karyawan PT. Lotte Shopping Indonesia. Laporan ini bisa muncul setelah melakukan transaksi yang dilakukan pada saat transaksi absensi.

\section{SIMPULAN DAN SARAN}

Berdasarkan hasil pembahasan dan penelitian mengenai perancangan sistem informasi absensi karyawan berbasis java netbeans pada PT. Lotte Shopping Indonesia dapat diambil kesimpulan bahwa perancangan sistem informasi absensi karyawan pada PT. Lotte Shopping Indonesia selama ini masih menggunakan sistem manual, dengan dibuatnya sistem yang baru, yang dirancang menggunakan bahasa pemrograman java netbeans IDE, dengan menggunakan database MySQL, sehingga pekerjaan lebih efektif dan efisien dalam pengolahan data. Komputerisasi sebagai alternative pemecahan masalah dalam menangani masalah-masalah yang terdapat pada sistem informasi absensi karyawan yang sedang berjalan saat ini diharapkan dapat membentuk dan merupakan salah satu alternatif pemecahan masalah. Sehingga proses pengolahan data yang ada lebih terkontrol sehingga proses pengolahan data yang ada lebih terkontrol dengan sistem komputerisasi ini sangat memudahkan saat pembuatan laporan dan penyimpanan data dengan harddisk dapat menghemat kertas dan waktu terjamin keamanannya karena dapat digunakan berulang ulang kali dan diperbaharui.

\section{UCAPAN TERIMAKASIH}

Ucapan terima kasih dari penulis sampaikan terutama untuk Bapak Imam Himawan, M.Kom. Sebagai pembimbing materi, Ibu Lin Suciani Astuti, S.Si,M.A. Sebagai pembimbing teknik, ibu Mei Lestari, M.kom selaku Ketua Program Studi Informatika, ibu shendy paramitha, SE selaku Manager yang telah memberi kesempatan untuk menganalisa dan menjadikan objek tempat penelitian saya sehingga tugas akhir saya bisa diselesaikan pada perusahaannya. Terima kasih pula kepada kedua orang tua saya yang selalu memberikan semangat dan doa yang tiada henti untuk saya, dan terima kasih kepada semua untuk waktu dan tempat yang telah ikut terlibat penelitian di dalam tugas akhir saya saya.

\section{DAFTAR PUSTAKA}

A.S. 2016. "Rekayasa Perangkat Lunak Terstruktur Dan Berorientasi Objek." in Informatika Bandung.

Agus, Mulyanto. 2009. "Sistem Informasi Konsep Dan Aplikasi." Yogyakarta: Pustaka Pelajar.

Bay Haqi. 2019. Aplikasi Absensi Dosen Dengan Java Dan Smarphone. PT. Elex Media Komputindo.

Hasibuan Malayu S.P. 2009. Organisasi Dan Motivasi Dasar Peningkatan Produktifitas. Bumi Aksar. jakarta.

Ida Nuraida, S. E. 2008. "Manajemen Administrasi Perkantoran." Kanisius 16.

Jogiyanto. 2008. "Metodologi Penelitian Sistem Informasi. Yogyakarta: CV. Andi Offset."

Mulyani, Sri. 2016. "Analisis Sistem." Pengertian Analisis Sistem 38.

Oktafianto, dan Muhammad, and Muslihudin. 2016. "Analisis Dan Perancangan Sistem Informasi Menggunakan Model Terstruktur Dan UML - Muhamad Muslihudin, Oktafianto - Google Buku." Analisis Dan Perancangan Sistem Informasi Menggunakan Model Terstruktur Dan Uml 118. Retrieved (https://books.google.co.id/books?id=2 SU3DgAAQBAJ\&printsec $=$ frontcover $\& \mathrm{hl}=\mathrm{id} \# \mathrm{v}=$ onepage $\& \mathrm{q} \& \mathrm{f}=$ false $)$.

Rusmawan, Uus. 2019. Teknik Penulisan Tugas Akhir Dan Skripsi Pemrograman. PT Elex Media Komputindo.

Soeherman, Bonnie dan Marion Pinontoan. 2008. Designing Information System Concept \& Cases with Visio. 